\title{
LA GESTIÓN EFICIENTE DE RECURSOS \\ EN LA UNIÓN EUROPEA: ALCANCE E IMPACTO \\ DE LA NORMATIVA EUROPEA PARA UNA \\ ECONOMÍA MÁS SOSTENIBLE Y CIRCULAR \\ BEATRIZ PÉREZ DE LAS HERAS ${ }^{1}$ \\ beatriz.perez@deusto.es
}

\section{Resumen}

Como región altamente dependiente del abastecimiento exterior, la Unión Europea (UE) considera el uso eficiente de recursos como una prioridad de primer nivel para garantizar la protección medioambiental, la prosperidad económica y el bienestar social. En respuesta a este desafío, múltiples marcos estratégicos y acciones específicas en sectores clave promueven el cambio hacia un nuevo modelo de economía más sostenible y circular, reflejo de la Estrategia Europa 2020. Los progresos observados, aun relevantes, resultan escasos y asimétricos, según los ámbitos y los Estados miembros considerados, por lo que serán necesarios esfuerzos adicionales para alcanzar la meta de un sistema económico en el que todos los recursos se aprovechan y se reciclan para volverlos a utilizar. Simultáneamente a su acción interna, la UE se esfuerza en promover la gestión eficiente de recursos a nivel global, especialmente en países pobres. Sin embargo, las incoherencias observadas y la falta de una estrategia específica para su acción exterior merman la credibilidad de la UE como actor de desarrollo sostenible, a la espera de un marco más holístico de actuación.

1 Catedrática de Derecho de la Unión Europea. Departamento de Derecho Transnacional, Universidad de Deusto. 


\title{
Palabras clave
}

Uso eficiente de recursos; economía circular; reducción de emisiones; desarrollo sostenible; coherencia de políticas para el desarrollo.

\section{RESOURCE-EFFICIENCY IN THE EUROPEAN UNION: SCOPE AND IMPACT OF THE EUROPEAN LEGISLATION FOR A MORE SUSTAINABLE AND CIRCULAR ECONOMY}

\begin{abstract}
As a highly dependent region on foreign supply, the European Union (EU) has set resource-efficiency as a first level priority to ensure environmental protection, economic prosperity and social welfare. To address this challenge, multiple strategic frameworks and specific policies in key sectors promote the shift to a new model of more sustainable and circular economy, reflecting the Europe 2020 Strategy. Though relevant, progresses are scarce and asymmetric, depending on the area and the Member States concerned. Therefore, additional efforts will be needed to achieve the goal of an economic system in which all resources are used and pumped back into productive use again. Besides its domestic policy, the EU also strives to promote efficient-resource management globally, especially in poor countries. However, some inconsistencies and the lack of a specific strategy for its external action undermine the EU's credibility as an actor of sustainable development, while waiting for a more holistic framework for action.
\end{abstract}

\section{Keywords}

Resource-efficient use; circular economy; reduction of emissions; sustainable development; policy coherence for development.

\section{L'UTILISATION EFFICACE DES RESSOURCES DANS L'UNION EUROPÉENNE: PORTÉE ET IMPACT DE LA LÉGISLATION EUROPÉENNE POUR UNE ÉCONOMIE PLUS DURABLE ET CIRCULAIRE}

\section{Résumé}

Comme région très dépendante de l'offre étrangère, l'Union Européenne (UE) a érigé l'utilisation efficace des ressources au rang de priorité de premier niveau pour assurer la protection de l'environnement et la prospérité économique et sociale. En réponse à ce défi, plusieurs cadres stratégiques et des actions spécifiques dans les secteurs clés favorisent le passage à un nouveau modèle d'économie plus durable et circulaire, en tant que réflexe de la Stratégie Europe 2020. Bien qu'importants, les progrès sont rares et asymétriques, selon les secteurs et les États membres concernés, 
de sorte que des efforts supplémentaires seront nécessaires pour atteindre l'objectif d'un système économique dans lequel toutes les ressources sont utilisées et recyclés pour leur réutilisation. Parallèlement à son action interne, l'UE cherche à promouvoir une gestion efficace des ressources à l'échelle mondiale, en particulier dans les pays pauvres. Cependant, les incohérences observées et le manque d'une stratégie spécifique pour son action extérieure portent atteinte à la crédibilité de l'UE en tant qu'acteur du développement durable, en attendant un cadre plus holistique d'action.

\section{Mots clés}

Utilisation efficace des ressources; économie circulaire; réduction des émissions; développement durable; cohérence des politiques pour le développement. 


\section{SUMARIO}

I. INTRODUCCIÓN. II. HACIA UNA GOBERNANZA MÁS SOSTENIBLE DE PRODUCCIÓN Y CONSUMO EN LA UE: 1. Hacer más con menos y economía circular: un largo camino al nuevo modelo de crecimiento económico; 2 . El control de emisiones: objetivos insuficientes de reducción en el tránsito hacia una economía hipocarbónica. III. LA DIMENSIÓN EXTERIOR DE LA AGENDA EUROPEA: LA FALTA DE UNA ESTRATEGIA COHERENTE CON EL DESARROLLO SOSTENIBLE: 1. EI desarrollo sostenible como marco jurídico de la cooperación internacional para el uso eficiente de recursos; 2 . Incoherencias e insuficiencias en la acción exterior de la UE; 3 . Iniciativas y propuestas para una contribución internacional más consistente. IV. CONCLUSIONES.

\section{INTRODUCCIÓN}

Unido al cambio climático, la escasez de recursos constituye un desafío de enormes y múltiples dimensiones al que debe responder la comunidad internacional en su conjunto. En los últimos 50 años, la extracción y el consumo mundial de recursos han experimentado un incremento de más de un $50 \%$ y las perspectivas apuntan a que la demanda global seguirá aumentando, pudiendo llegar a triplicarse para $2050^{2}$. El aumento de la población mundial, estimada en 9000 millones de personas para 2050, y el progresivo deterioro medioambiental ejercen una enorme presión sobre recursos como el agua, las fuentes de energía, la tierra, los alimentos y los minerales. En 2007, el uso global de estos recursos superó ya la biocapacidad del planeta en un $50 \%$, en un contexto en el que la población mundial era de 6600 millones $^{3}$. Un informe

2 Jo LEINEN, «A European response to the resource and climate challenge», Challenge Europe, núm. 22, 2014, pp. 50-55, p. 50.

3 La biocapacidad es un indicador que mide la capacidad potencial del planeta para suministrar recursos naturales. El dato referido a 2007 significa que el planeta 
reciente del Panel Intergubernamental sobre Cambio Climático (IPCC, en sus siglas en inglés) alerta de que la demanda de alimentos continuará creciendo a un ritmo de un $14 \%$ por década, mientras que la producción agraria disminuirá un $2 \%$, debido principalmente a los efectos del cambio climático, de especial incidencia en los países en desarrollo ${ }^{4}$. La pérdida de biodiversidad y la degradación medioambiental conllevan, además, importantes consecuencias geopolíticas para la seguridad global'5

El uso intensivo de recursos cada vez más escasos lleva asociado un incremento de los precios, al tiempo que genera incertidumbre sobre la futura disponibilidad de los mismos. Estas circunstancias y perspectivas suscitan enormes desafíos para la Unión Europea (UE), al tratarse de una región altamente dependiente del exterior. En efecto, Europa sigue siendo el mayor importador mundial de recursos por persona y su economía sigue gravitando en gran medida en el abastecimiento exterior de energía, alimentos y materias primas. Esta dependencia hace a la UE especialmente vulnerable a la alta volatilidad de precios y la falta o escasez de suministros, con el consiguiente impacto negativo que todo ello acarrea en la competitividad industrial y el crecimiento económico ${ }^{6}$.

Para afrontar estos retos, la UE ha adoptado en su ámbito interno múltiples marcos plurinacionales e iniciativas específicas que promueven la gestión eficiente de recursos, esto es, la generación de más valor utilizando menos recursos y consumiendo de modo diferente. El objetivo último de la estrategia europea es promover un nuevo modelo más sostenible de producción y de consumo, disociando el crecimiento económico del uso de recursos y las emisiones de gases de efecto invernadero (GEI). Más concretamente, bajo el título "Vivir bien, respetando los límites de nuestro planeta», el $7^{\circ}$ Programa General de Acción de la Unión en Materia de Medio Ambiente concreta la

necesita un año y medio para generar los recursos que se consumen en un año. Véase WORLD WILDLIFE FUND, Living Planet. Report 2010, pp. 7-9, 32-45, disponible en http://d2ouvy59p0dg6k.cloudfront.net/downloads/wwf_lpr2010_ lr_en.pdf (consultado por última vez el 20.09.2016).

4 IPPC, Climate Change 2014. Synthesis Report. Contribution of Working Groups I, II and III to the Fifth Assessment Report of the Intergovernmental Panel on Climate Change, 2015, pp. 65 y 69, disponible en https:/www.ipcc.ch/report/ar5/syr/ (consultado por última vez el 20.09.2016).

5 Oriol SOLÁ PARDELL, «Desplazados medioambientales. Una nueva realidad», Cuadernos Deusto de Derechos Humanos, núm. 66, 2012, pp. 13-116.

6 EUROPEAN ENVIRONMENTAL AGENCY, Intensified global competition for resources (GMT 7), SOER 2015, pp. 3-4, disponible en http://www.eea.europa.eu/ soer-2015/global/competition (consultado por última vez el 20.09.2016). 
visión de la UE para 2020, un escenario en el que la prosperidad económica y el bienestar social de Europa estarán ineludiblemente ligados a su entorno natural ${ }^{7}$.

No obstante, la acción interna, por sí misma, resulta insuficiente, si no se aborda simultáneamente la dimensión exterior del desafío que supone la escasez progresiva de recursos, dado su alcance global y el impacto negativo que tiene especialmente en la sociedad y el medioambiente de países en desarrollo. Con este propósito, la UE se esfuerza en cooperar para fomentar el uso eficiente de recursos fuera de sus fronteras, atendiendo así a los compromisos asumidos en los foros internacionales y en consonancia con la promoción del desarrollo sostenible como objetivo transversal de todas sus políticas.

Este artículo analiza la acción de la UE dirigida a la gestión eficiente de recursos, tanto en su dimensión interna, como externa, identificando las normas jurídicas de base y valorando el impacto y la coherencia de las iniciativas europeas. Una primera parte se adentra en el análisis de las principales medidas adoptadas por la UE en su ámbito interno. Concretamente, el estudio se detiene, en particular, en aquellos aspectos considerados estratégicos en la apuesta europea por un nuevo modelo más sostenible de producción y consumo, paradigma de una economía circular e hipocarbónica. El examen revela que, a pesar de los importantes logros conseguidos, especialmente en términos de menor consumo de materiales y reducción de contaminación, el capital natural de Europa sigue sin estar suficientemente protegido, lo que es debido principalmente, entre otras insuficiencias, a la falta de una implementación efectiva de las acciones propuestas. La segunda parte valora el alcance de la cooperación internacional de la UE en aras a promover la gestión eficiente de recursos como componente esencial del desarrollo sostenible y la reducción de la pobreza. Como principal hallazgo, se constata la falta de una estrategia específica en este ámbito, lo que explica en gran medida las incoherencias entre las prioridades de la UE y sus propias acciones en el exterior. El estudio concluye que vivir bien dentro de los límites ecológicos requerirá de una estrategia más holística por parte de la UE, que abarque consistentemente su acción interna y su propia política exterior, estableciendo sinergias coherentes entre ambas dimensiones.

7 Decisión 1386/2013/UE de 20 de noviembre de 2013 relativa al Programa General de Acción de la Unión en Materia de Medio Ambiente hasta 2020 «Vivir bien, respetando los límites de nuestro planeta» (DO L354, de 28 de diciembre de 2013, p. 171). 


\section{HACIA UNA GOBERNANZA MÁS SOSTENIBLE DE PRODUCCIÓN Y CONSUMO EN LA UE}

El 7o Programa de Acción en Materia de Medio Ambiente establece, como uno de sus objetivos prioritarios para 2020 "convertir a la Unión en una economía hipocarbónica, eficiente en el uso de los recursos, ecológica y competitiva» ${ }^{8}$. La consecución de este objetivo conlleva una transformación del sistema tradicional de producción y consumo lineal, basado en un uso continuo de recursos, a un modelo de economía circular, asentado en un menor consumo y en el que los recursos se mantienen el mayor tiempo posible en uso, utilizándose y reciclándose al final de su vida útil. El concepto de economía circular tiene su origen en la ecología industrial, una teoría académica que se desarrolla en la década de los setenta, que es objeto de una creciente atención y que aboga por la reorganización de los sistemas industriales conforme a pautas propias de los ecosistemas naturales. Conforme a esta filosofía de organización, la noción de residuos desaparece, ya que los desperdicios que no responden a las necesidades iniciales de unos consumidores vuelven a introducirse en el circuito económico, transformándose en recursos para otros. Los productos son diseñados para ser reutilizados y/o reparados, y sus componentes vuelven a formar parte de los ciclos naturales o industriales con un consumo mínimo de energía?

8 Ibid., art. 2, 1 b de la Decisión 1386/2013/UE.

9 Sébastien SAUVÉ, Sophie BERNARD, Pamela SLOAN, «Environemntal sciences, sustainable development and circular economy: alternative concepts for trans-disciplinary research», Environmental Development, núm. 17, 2016, pp. 48-56, p. 53. Sobre el concepto de economía circular, las distintas escuelas de pensamiento y su evolución, véase también Felix PRESTON, «A global redesign? Shaping the circular economy», Energy, Environment and Resource Governance, núm. 2, 2012, pp. 1-20; ELLEN MACARTHUR FOUNDATION, Towards the circular economy: economic and business rationale for an accelerated transition, 2012, disponible en https://www. ellenmacarthurfoundation.org/publications (consultado el 20.09.2016); WORLD ECONOMIC FORUM, Towards the circular economy: accelerating the scale-up across global supply chains, 2014, en particular, pp. 13-20, disponible en http://www3.weforum.org/docs/WEF_ENV_TowardsCircularEconomy_Report_2014.pdf (consultado por última vez el 20.09.2016); Luis GONZÁLEZ VAQUÉ, “¿Del consumo sostenible a una economía circular?», Revista CESCO de Derecho de Consumo, núm. 17, 2016, pp.179-191; Patrizia GHISELLINI, Catia CIALANI y Sergio ULGIATI, "A review on circular economy: the expected transition to a balanced interplay of environmental and economic systems», Journal of Cleaner Production, núm. 114, 2016, pp. 11-32. 
Este cambio de paradigma requiere, por tanto, modificaciones sustanciales de los comportamientos clásicos de producción y consumo en el contexto de una nueva gobernanza en la que participen y se impliquen los responsables políticos, las empresas, los consumidores y la sociedad civil en general. Asimismo, en la transición hacia una economía hipocarbónica, la adopción de medidas dirigidas a reducir los niveles de emisión de gases de efecto invernadero (GEI) e incrementar la eficiencia energética constituyen un complemento clave de una economía circular y de los nuevos patrones de producción y consumo más sostenibles.

\section{HACER MÁS CON MENOS Y ECONOMÍA CIRCULAR: UN LARGO CAMINO AL NUEVO MODELO DE CRECIMIENTO ECONÓMICO}

La utilización eficiente de recursos es un elemento clave de la agenda de la UE para la competitividad global, la recuperación sostenible de la crisis económica y la creación de empleo, como así se expresa claramente en la Estrategia Europa $2020^{10}$. Una de las siete iniciativas emblemáticas adoptadas para implementar esta Estrategia es, precisamente, la relativa a "Una Europa que utilice eficazmente los recursos» ${ }^{11}$. Este documento estratégico establece el marco para impulsar la transición hacia un modelo que permita desvincular el crecimiento económico del uso de los recursos y de sus impactos medioambientales, reduciendo el consumo general de los mismos, desarrollando nuevos productos y servicios, disminuyendo y reutilizando los residuos y optimizando los procesos de producción y de consumo. Todo ello debería contribuir a estimular la innovación tecnológica y la creación de empleo en el sector de las tecnologías verdes, así como a mantener el comercio en la UE, proporcionando a los consumidores productos más sostenibles. El reconocimiento de la necesidad de gestionar mejor los recursos en Europa se encuadra, por tanto, dentro de una estrategia económica global, más allá de una actuación puramente medioambiental ${ }^{12}$.

10 COMISIÓN EUROPEA, «Europa 2020. Un estudio para un crecimiento inteligente, sostenible e integrador», COM (2010) 2020 final, 3.3.2010, p. 6.

11 COMISIÓN EUROPEA, «Una Europa que utilice eficazmente los recursos. Iniciativa emblemática con arreglo a la Estrategia Europa 2020», COM (2011) 21 final, 26.1.2011, pp. 3-5.

12 Doreen FEDRIGO-FAZIO, David BALDOCK, Andrew FARMER y Sonja GANTIOLER, «EU natural resources policy: signposts on the roadmap to sustainability», Directions in European environmental policy, núm. 2, Mayo 2011, pp. 1-18, p. 2, disponible en http://www.ieep.eu/assets/800/DEEP_NaturalResources.pdf (consultado por última vez el 20.09.2016). 
Uno de los objetivos principales de esta iniciativa es proporcionar seguridad a los inversores y a los esfuerzos de innovación, estableciendo un marco a largo plazo que garantice que todas las políticas y acciones incorporen progresivamente un enfoque basado en la utilización eficiente de los recursos. Los elementos principales de este marco se han venido concretando en diversas hojas de ruta y planes plurianuales de acción para los sectores clave ${ }^{13}$. En particular, la hoja de ruta Hacia una Europa eficiente en el uso de los recursos ${ }^{14}$ y la hoja de ruta Hacia una economía hipocarbónica ${ }^{15}$ constituyen los pilares esenciales de esta iniciativa emblemática, ya que la utilización más eficiente de los recursos se considera clave para conseguir los objetivos en materia de cambio climático. En concreto, ambos documentos comparten la visión de una Europa que, en 2050, crecerá gestionando de forma sostenible sus recursos, al tiempo que habrá reducido sus emisiones en un $80 \%$ con respecto a los niveles de 1990, contribuyendo con todo ello a una transformación económica global. Ambos marcos estratégicos sitúan, por tanto, la acción de la UE más allá de 2020, estableciendo, no obstante, objetivos intermedios y medidas específicas para alcanzarlos.

En lo que respecta, en concreto, a la gestión eficiente de recursos, la hoja de ruta específica establece los objetivos que conseguir para 2020, e identifica las actuaciones necesarias en cada sector para poner en marcha el proceso de transformación de la economía hacia pautas de producción y consumo más sostenibles. Conforme al lema "hacer más con menos», la pretensión última de la acción europea es reducir la cantidad de recursos empleada por las empresas y los agentes económicos en general, disociando su utilización de la producción y la productividad. En este sentido, cabe destacar que, desde 2000, se observa ya en Europa una lenta pero progresiva desvinculación entre consumo de materiales y volumen de producción e índice de productividad, una tendencia favorecida por la crisis económica a partir de 2008, así como por la relocalización de la extracción y fabricación de materiales en otras regiones del mundo ${ }^{16}$. En efecto, según datos recientes de Eurostat, mientras que el consumo de materiales se redujo de 15,4

13 El elenco de estas actuaciones sectoriales se recoge en el Anexo I del Programa de Trabajo de la Comisión Europea para 2010 (COM (2010) 135 final, 31.3.2010) y en los Anexos al Programa de Trabajo de la Comisión Europea para 2011 (COM (2010) 623 final, 27.10.2010). Información disponible en http://ec.europa.eu/resource-efficient-europe/index_en.htm (consultado por última vez el 20.09.2016).

14 COM (2011) 571 final, 20.9.2011.

15 COM (2011) 112 final, 8.3. 2011.

16 Véase EUROPEAN ENVIRONMENTAL AGENCY, The European environment. State and Outlook 2015. Synthesis report, 4. Resource efficiency and the low-carbon econ- 
toneladas en 2002 a 13,3 toneladas en 2014 en el conjunto de los 28 Estados miembros, la productividad, en términos de PIB y consumo doméstico de materiales, se incrementó del 1,52 €/ kg en 2002 al 1,95€/ kg en $2014{ }^{17}$. Según estimaciones de la propia Comisión Europea, hay todavía margen para avanzar aún más en esta línea y resulta factible conseguir una disminución del $17 \%$ en el uso de materiales y un incremento simultáneo del 30\% de productividad para 2030, al tiempo que se pueden crear entre 1,4 y 2,8 millones de empleos ${ }^{18}$.

Con respecto, en concreto, a las materias primas, su importancia estratégica como recursos clave, tanto para la industria como para el conjunto de la sociedad, está ampliamente reconocida en varias iniciativas específicas, como la Iniciativa Materias Primas, relativa principalmente a minerales para la construcción, metales de alta tecnología y materias primas secundarias, éstas últimas resultantes del reciclado. El objetivo de esta iniciativa es establecer una estrategia integral en materias primas en el marco de la UE, asentada en tres principios fundamentales: garantizar el acceso a materias primas a nivel internacional, promover el suministro sostenible desde fuentes europeas de origen e impulsar el uso eficiente de recursos promoviendo su reciclado para reducir el consumo europeo de materias primas ${ }^{19}$.

omy, p. 6, disponible en http://www.eea.europa.eu/soer-2015/synthesis (consultado por última vez el 20.09.2016).

17 El consumo eficiente de recursos varía, sin embargo, según los Estados miembros, debido principalmente a su diferente estructura económica (industrial o de servicios). Así, mientras España incrementó su productividad en un $127 \%$ en el período considerado, Malta y Estonia lo redujeron en un 19\%. Véase EUROSTAT, Resource effciency scoreboard 2015, 2016, pp. 11 y 13, disponible en http://ec.europa.eu/environment/resource_efficiency/targets_indicators/scoreboard/index_en.htm (consultado por última vez el 20.09.2016).

18 DOCUMENTO DE TRABAJO DE LA COMISIÓN EUROPEA, Analysis of an EU target for resource productivity, SWD (2014) 211 de 2 de julio de 2014, pp. 9, 11 y 15.

19 COMISIÓN EUROPEA, «La iniciativa de las materias primas: cubrir las necesidades fundamentales en Europa para generar crecimiento y empleo», COM (2008) 699 final, 4.11.2008. La Comisión Europea publica periódicamente una lista de materias primas a las que resulta de aplicación las actuaciones de esta iniciativa; la última actualización es de 2014, en la que se incluyen 20 materias primas fundamentales para la industria europea. Véase COMISIÓN EUROPEA, «Sobre la revisión de la lista de las materias primas fundamentales para la UE y la aplicación de la iniciativa de materias primas», COM (2014) 297 final, 26.5.2014, Anexo 1. 
Evitar el uso de productos químicos peligrosos y promover una química verde es otra de las acciones promovidas por la UE para proteger recursos esenciales, como el suelo o el agua. El denominado "Reglamento REACH» impulsa la sustitución de estos productos químicos peligrosos por alternativas más seguras y viables desde el punto de vista tecnológico y económico ${ }^{20}$.

Muchas empresas en Europa han empezado ya a adoptar medidas para garantizar un uso más eficiente de los recursos, en la línea de las acciones estratégicas propuestas por la Comisión e implementadas a continuación por los Estados miembros. Un ejemplo considerado como buena práctica es la denominada «simbiosis industrial», por la que los residuos de algunas empresas son utilizados como recursos por otras ${ }^{21}$. Según cálculos de la Comisión Europea, esta práctica podría suponer un ahorro alrededor de 1400 millones de euros al año y generar un volumen de negocios de 1600 millones de euros ${ }^{22}$.

La aspiración de «hacer más con menos» se extiende también a los consumidores y la sociedad civil en general. Para responder a este objetivo, la UE ha adoptado diversas iniciativas y campañas de concienciación, como la Generation Awake, dirigida a jóvenes europeos y familias con niños pequeños, que intentan propiciar cambios en los hábitos de consumo y la gestión de re$\operatorname{cursos}^{23}$. Asimismo, desde la UE se apoyan y cofinancian iniciativas nacionales y locales que promueven nuevas modalidades de consumo, como el denomi-

20 Reglamento CE 1907/2006 de 18 de diciembre de 2006 relativo al registro, la evaluación, la autorización y la restricción de las sustancias y los preparados químicos (REACH), por el que se crea la Agencia Europea de sustancias y preparados químicos, se modifica la Directiva 1999/45/CE y se derogan el Reglamento CEE 793/93 del Consejo, el Reglamento 1488/94 de la Comisión, así como la Directiva 76/769/CEE del Consejo y las Directivas 91/155/CEE, 93/67/CEE, 93/105/CE de la Comisión (DO L 396, de 30 de diciembre de 2006, p.1). La última modificación de este Reglamento ha entrado en vigor el 1 de abril de 2016. Véase Reglamento UE 317/2014 de 27 de marzo de 2014 (DO L 93, de 28 de marzo de 2014, p.24).

21 Un modelo de simbiosis industrial es el que ofrece, por ejemplo, el programa británico National Industrial Symbiosis Programme (NISP), que engloba a unas 14500 empresas de diferentes tamaños, a las que se ofrece oportunidades de colaboración y asesoramiento sobre soluciones de gestión sostenible de recursos. Más información disponible en http://ec.europa.eu/environment/ecoap/about-eco-innovation/experts-interviews/212_es (consultado por última vez el 20.09.2016).

22 COMISIÓN EUROPEA, op. cit., nota 14, p. 6.

23 Véase COMISION EUROPEA, The consumption guide, 2014, disponible en http://ec.europa.eu/environment/generationawake/pdf/generationawake-consumption-guide_en.pdf (consultado por última vez el 20.09.2016). 
nado "consumo colaborativo», consistente en intercambiar y compartir bienes y servicios ${ }^{24}$.

Con todo, a pesar de las tendencias favorables hacia un menor y más eficiente uso de recursos y materiales, el nivel de consumo en el conjunto de la UE sigue siendo intensivo, lo que, unido a una perspectiva de posible recuperación económica, podría hacer revertir la tendencia descendente de los últimos ocho años. Esta eventualidad debería servir de incentivo para acelerar el tránsito hacia un sistema de economía circular, en el que los recursos se mantengan durante el mayor tiempo posible y se generen pocos residuos. Con ese propósito, en diciembre de 2015, la Comisión Europea adoptó un nuevo paquete de medidas y un plan de acción que incluye y refuerza las actuaciones específicas en algunos sectores clave ${ }^{25}$. En la progresión hacia el nuevo paradigma, acciones como la ecoinnovación, el diseño ecológico y el reciclado se consideran instrumentos ineludibles para fomentar una producción y un consumo más sostenibles.

La ecoinnovación constituye, en efecto, un componente clave de un modelo económico verde y sostenible. Para impulsarla, la UE ha puesto en marcha el Plan de Acción sobre Ecoinnovación ${ }^{26}$. Este documento estratégico está principalmente ligado a la iniciativa emblemática «Unión por la innovación» de la Estrategia Europea 202027. La pretensión es que las políticas de innovación se centren también en las tecnologías verdes y la innovación ecológica, resaltando así el papel de la política medioambiental como factor de progreso económico. De hecho, las industrias ecológicas representan actualmente uno de los sectores con mayor crecimiento en la UE y conforman un ámbito en el que las empresas europeas lideran el mercado mundial, especialmente el de reciclaje. La ecoinnovación es considerada, por ello, un instrumento fundamental para impulsar la productividad y la competitividad de las empresas a nivel global y generar empleo. El objetivo para los próximos años es promover

24 La economía colaborativa está creciendo rápidamente en Europa. Su impulso y desarrollo equilibrado constituye en estos momentos una de las acciones prioritarias de la estrategia relativa al mercado único. COMISION EUROPEA, «A European agenda for the collaborative economy», COM (2016) 356 final, 2.6.2016. COMISIÓN EUROPEA, «Paquete sobre la economía circular: preguntas y respuestas", disponible en http://europa.eu/rapid/press-release_MEMO-15-6204_es.htm (consultado por última vez el 20.09.2016); "Cerrar el círculo: un plan de acción de la UE para la economía circular», COM (2015) 614 final, 2.12.2015.

26 COMISIÓN EUROPEA, «Innovación para un futuro sostenible. Plan de Acción sobre Ecoinnovación (Eco-AP)», COM (2011) 899 final, 15.12.2011.

27 COMISIÓN EUROPEA, «Iniciativa emblemática de Europa 2020. Unión por la innovación», COM (2010) 546 final, 6.10.2010. 
aún más esta línea de acción para sacar provecho de un mercado mundial que representa un billón de euros para las ecoindustrias ${ }^{28}$. Para conseguirlo, serán necesarias inversiones públicas y privadas. Con el fin de incentivarlas, la UE ha puesto en marcha diversos instrumentos financieros, como el programa Horizonte 2020, los Fondos Estructurales y de Inversión, o el Fondo para Inversiones Estratégicas, entre otros ${ }^{29}$.

Mejorar las características medioambientales de los productos a través de su diseño e informar a los consumidores para que elijan mejor constituyen acciones que también contribuyen a optimizar el uso de los recursos. El objetivo último es garantizar la posibilidad de reutilizarlos, recuperarlos o reciclarlos, asegurando así su durabilidad y la reducción del consumo energético. En este sentido, la Directiva 2005/32/CE, sobre el diseño ecológico, obliga a los fabricantes a tener en cuenta el consumo de energía y otros aspectos medioambientales durante la fase de diseño de los productos que consuman una gran cantidad de energía, como calentadores de agua, calderas, ordenadores o electrodomésticos ${ }^{30}$. Su fin principal es reducir el consumo de energía, pero también tiene en cuenta otros factores como las emisiones, el consumo de agua, los residuos y la posibilidad de reciclaje. En 2009, la Directiva fue objeto de una modificación que extendió su ámbito de aplicación a productos que no utilizan energía, pero cuyo uso tiene incidencia directa en el consumo de la misma, como son las ventanas o los aparatos que utilizan agua ${ }^{31}$. Como acciones futuras en este marco, la Comisión tiene previsto promover la repara-

28 Annika AHTONEN y Serban CHIOREAN-SIME, «Green revolution: making eco-efficiency a driver for growth», European Policy Centre (EPC) Issue Paper, núm. 68, 2012, pp. 1-67, pp. 4-6.

29 En concreto, para el período 2016-2017, el programa Horizonte 2020 contempla una importante iniciativa sobre "Industria 2020 en la economía circular», con una dotación financiera de más de 650 millones de euros, en sectores como el medio ambiente, la eficiencia de recursos, la seguridad alimentaria, la agricultura sostenible y la biotecnología. Véase COMISION EUROPEA, «Horizon 2020. Work Programme 2016-2017. 17. Cross-cutting activities (focus áreas)», disponible en http://ec.europa.eu/research/participants/data/ref/h2020/wp/2016_2017/main/h2020-wp1617focus_en.pdf (consultado por última vez el 20.09.2016); Antonella BASSI, «La economía circular: un impulso a la inversión en Europa», 21 Noticias, 30 de marzo de 2016, disponible en http://www.21 noticias.com/2016/03/la-economia-circular-impulso-la-inversion-europa/ (consultado por última vez el 20.09.2016).

30 Directiva 2005/32/CE de 6 de julio de 2005 (DO L 191, de 22 de julio de 2005, p. 29).

31 Directiva 2009/125/CE de 21 de octubre de 2009, por la que se instaura un marco para el establecimiento de requisitos de diseño ecológico aplicables a los productos 
ción, la durabilidad y el reciclado de todos los productos que sean pertinentes para la economía circular ${ }^{32}$. En la misma línea, el reglamento sobre el etiquetado ecológico tiene como objetivo influir en las opciones de producción y consumo proporcionando información sobre la huella ecológica de los productos $^{33}$. A diferencia de la directiva sobre diseño ecológico, este reglamento establece un sistema voluntario que incita a las empresas a comercializar productos y servicios conforme a una serie de criterios medioambientales establecidos por el Comité de Etiquetado Ecológico de la UE y que se publican en el Diario Oficial de la UE. Los criterios tienen en cuenta todo el ciclo de vida del producto o servicio, desde su obtención o extracción, hasta su elaboración, empaquetado, transporte, consumo y, eventualmente, reciclaje. Los productos y servicios que reciben la etiqueta ecológica llevan un logo en forma de flor, que permite identificarlos fácilmente por los consumidores ${ }^{34}$.

Los criterios ecológicos, aplicables a productos con un impacto medioambiental significativo, también afectan a los procesos de contratación pública. A través de distintas iniciativas, la UE está promoviendo en este ámbito la contratación pública ecológica, una política voluntaria de apoyo a las autoridades públicas en la adquisición de productos, servicios y obras con un reducido impacto medioambiental. En 2004, las Directivas 2004/17/CE y 2004/18/ CE sobre contratación pública, fueron las primeras en contener referencias específicas a consideraciones medioambientales en el proceso de adjudicación de contratos ${ }^{35}$. Cuatro más tarde, la Comisión publicó la comunicación

relacionados con la energía (refundición) (DO L 285, de 31 de octubre de 2009, p. $10)$.

32 Véase el Anexo 1 del documento COM (2015) 614 final, op. cit., nota 25.

33 Reglamento CE/66/2010 de 25 de noviembre de 2010 relativo a la etiqueta ecológica de la UE (DO L 27, de 30 de enero de 2010, p. 1).

34 Actualmente, la etiqueta ecológica se aplica a productos de limpieza, electrodomésticos, artículos de papelería, prendas de vestir, productos para el hogar y el jardín, lubricantes y algunos servicios como alojamientos turísticos. Información disponible en http://ec.europa.eu/environment/ecolabel/\# (consultado por última vez el 20.09.2016).

35 Como resultado de las modificaciones introducidas en esta normativa, se adoptaron en 2014 tres nuevas directivas que han simplificado los procedimientos y promueven así mismo un mayor uso de la contratación pública ecológica. Véase Directiva 2014/23/UE relativa a la adjudicación de contratos de concesión, Directiva 2014/24/ UE sobre contratación pública y por la que se deroga la Directiva 2004/18/CE y Directiva 2014/25/UE relativa a la contratación en los sectores de agua, energía, los transportes y los servicios postales y por la que se deroga la Directiva 2004/17/CE, de 24 de febrero de 2014 (DO L 94, de 28 de marzo de 2014, p. 1). 
«Contratación pública para un medio ambiente mejor» ${ }^{36}$, en la que proponía una serie de medidas para la aplicación de la contratación pública ecológica. Como resultado de esta iniciativa se han establecido, con carácter voluntario, criterios comunes de contratación ecológica en 10 sectores y el objetivo para 2020 es que al menos el 50\% de las licitaciones respondan a los criterios de la contratación pública ecológica ${ }^{37}$. Asimismo, la creación de redes de poderes adjudicatarios de contratos públicos constituye otra de las acciones en apoyo de la contratación ecológica ${ }^{38}$.

Convertir los residuos en recursos constituye otra de las piezas clave de una economía circular, en la que nada se desecha y todo se aprovecha. En efecto, una gestión eficaz de los mismos permite a la economía y a la sociedad extraer el máximo valor de los recursos, adaptar el consumo a las necesidades reales, reducir la demanda de materiales vírgenes y mitigar, al mismo tiempo, el uso energético y el impacto medioambiental. Constituye, además, una medida complementaria del ecodiseño y del etiquetado ecológico, ya que la gestión de residuos debe estar presente en todo el ciclo vital de los productos, no sólo al final del mismo ${ }^{39}$. La UE ha asumido el compromiso político de reducir la generación de residuos, reciclarlos para convertirlos en una fuente fiable de materias primas para la UE, recuperar energía únicamente de materiales no reciclables y eliminar los vertederos ${ }^{40}$. La pretensión no es nueva, ya que desde los años 90 la UE ha venido adoptando distintas medidas específicas en materia de gestión de recursos. En 2008, sin embargo, aprobó una norma de alcance más general, como es la Directiva Marco sobre Residuos, con arreglo a la cual los Estados miembros debían elaborar programas nacionales

36 COM (2008) 400 final, 16.7.2008.

37 COMISIÓN EUROPEA, Más inteligente y más limpio. Consumo y producción sostenibles, Oficina de Publicaciones de la Unión Europea, Luxemburgo, 2010, p. 14.

38 Por ejemplo, el programa interdepartamental de contratación de la ciudad de Viena (ÖkokaufWien) es considerado un modelo de buena práctica de contratación verde. Aplicado a diversos sectores como papel, aparatos eléctricos y electrónicos, construcción, vehículos y alimentos, su implementación ha supuesto a la ciudad de Viena un ahorro estimado de 17 millones de euros y una reducción de 30000 toneladas de CO2. Véase COMISION EUROPEA, «Resource efficient Europe», MEMO/11/43, 26 de enero de 2011, p. 2, disponible en http://europa.eu/rapid/press-release_MEMO-1143_en.htm?locale=en (consultado por última vez el 20.09.2016).

39 COMISIÓN EUROPEA, «Hacia una economía circular: un programa de cero residuos para Europa», COM (2014) 398 final, 2.7.2014, p. 10.

40 Véase el Programa General de Acción de la Unión Europea en Materia de Medio Ambiente, op. cit., nota 7, p. 184 y la Hoja de ruta hacia una Europa eficiente en el uso de recursos, op. cit., nota 14 , p. 9. 
de prevención de residuos para 2013. Este acto jurídico basa la política de gestión de residuos en el principio de jerarquía, priorizando así su prevención en primer lugar, seguido por su reutilización, reciclaje, recuperación y desecho, como última opción ${ }^{41}$. Más recientemente, el nuevo paquete de medidas sobre la economía circular incluye diversas propuestas normativas revisadas en materia de recursos ${ }^{42}$. En concreto, como objetivos para 2030, la Comisión ha establecido:

- La reutilización y el reciclado del 65\% de los residuos municipales, que son aquellos generados en los núcleos urbanos como resultado de actividades domésticas y comerciales.

- El reciclado del 75\% de los residuos de envases. Como objetivos intermedios, se contemplan el 60\% para 2020 y el $70 \%$ para 2025 .

- La reducción de los depósitos en vertederos a un máximo del 10\% de todos los residuos.

El desperdicio de alimentos es objeto también de atención especial en las nuevas propuestas normativas sobre residuos. Se estima que alrededor de 100 millones de toneladas de alimentos se desechan cada año en la UE. Conforme al nuevo marco normativo, los Estados miembros deberán adoptar medidas para evitar el despilfarro de alimentos en cada fase de la cadena alimentaria,

41 Directiva 2008/98/CE de 19 de noviembre de 2008 sobre los residuos y por la que se derogan determinadas Directivas (DO L312, de 22 de noviembre de 2008, p. 3). Véase José PERNAS GARCÍA, «La lucha contra la contaminación y la tendencia hacia la codificación del Derecho Ambiental Comunitario», Actualidad Jurídica Ambiental, núm.1, 2009, pp. 1-4; Francisco J. ARENAS CABELLO, «Las operaciones de gestión de residuos y sus modificaciones según la Directiva 2008/98, sobre residuos», Revista de Administración Pública, núm. 182, 2010, pp. 227-241.

42 Además de la Directiva Marco, las propuestas modifican otras cinco directivas que regulan la gestión de distintos tipos de residuos: la Directiva1999/31/CE de 26 de abril de 1999, relativa al vertido de residuos (DO L 182, de 16 de julio de 1999, p. 1); Directiva 2000/53/CE de 18 de septiembre de 2000, relativa a los vehículos al final de su vida (DO L 269, de 21 de octubre de 2000, p. 34); Directiva 2006/66/CE de 6 de septiembre de 2006, relativa a las pilas y acumuladores y por la que se deroga la Directiva 91/157/CEE (DO L266, de 26 de septiembre de 2006, p. 1); Directiva 2012/19/UE de 4 de julio de 2012 sobre residuos de aparatos eléctricos y electrónicos (DO L197, de 24 de julio de 2012, p. 38); Directiva 94/62/CE de 20 de diciembre de 1994, relativa a los envases y residuos de envases (DO L365, de 31 de diciembre de 1994, p.10). 
llevar a cabo un seguimiento de los niveles de residuos alimentarios y presentar periódicamente informes sobre los progresos realizados ${ }^{43}$.

Habrá que esperar todavía a la implementación efectiva de las nuevas medidas en los próximos años con objeto de poder valorar los resultados. Por el momento, los datos constatan que la sociedad europea sigue generando una gran cantidad de residuos, unas cinco toneladas por persona y año, de las que apenas se recicla un tercio ${ }^{44}$. Además, tanto las actuaciones como los resultados obtenidos hasta el momento varían considerablemente de unos Estados miembros a otros. Por ejemplo, seis Estados miembros han conseguido eliminar eficazmente los vertederos de residuos municipales, alcanzando niveles de reciclado del 85\% en algunas regiones. En otros, por el contrario, el 90\% de los residuos se depositan en vertederos y apenas el 5\% es reciclado. Así mismo, se observan divergencias en cuanto a los métodos nacionales empleados para calcular los residuos, lo que genera cierta inseguridad sobre los datos reales ${ }^{45}$. Esta asimetría en cuanto a implementación y resultados se ve propiciada en gran parte por la flexibilidad que dejan los objetivos trazados por la UE. Con objeto de reducir estas disparidades, el nuevo plan de acción de la Comisión Europea contempla también, como objetivo para 2017, la simplificación y la armonización de los procedimientos aplicados para el cálculo de los niveles de reciclado ${ }^{46}$.

Por tanto, puede afirmarse que, a pesar de los progresos observados en la reducción de residuos generados, su gestión eficiente precisará todavía de cambios y mejoras sustanciales. En esta misma línea, algunos Estados miembros tendrán que hacer un esfuerzo extraordinario para alcanzar, en particular, el objetivo de reciclar el 65\% de los residuos municipales para $2030^{47}$.

Aún lenta e incompleta, la implementación efectiva de pautas más sostenibles en el uso de recursos contribuye a la disminución de los impactos medioambientales derivados de su producción y consumo, respondiendo así también al objetivo de convertir a la UE en una economía hipocarbónica. La

43 Véase el Anexo al documento COM (2015) 614 final, sobre el plan de acción, op. cit., nota 25. Más información también disponible en http://ec.europa.eu/food/safety/ food_waste/stop/index_en.htm (consultado por última vez el 20.09.2016).

44 Véase EUROSTAT, «Estadísticas sobre residuos», 2015, disponible en http://ec.europa. eu/eurostat/statistics-explained/index.php/Waste_statistics/es (consultado por última vez el 20.09.2016).

45 DOCUMENTO DE TRABAJO DE LA COMISION EUROPEA, Impact Assessment, SWD (2014) 207 final de 4 de julio de 2014, pp. 15-20.

46 COMISIÓN EUROPEA, op. cit., nota 25, p. 10 y Anexo.

47 Véase información disponible en http://ec.europa.eu/environment/waste/studies/ (consultado por última vez el 20.09.2016). 
reducción de emisiones constituye, por ello, otro de los pilares de política a largo plazo de la iniciativa emblemática «Una Europa que utilice eficazmente los recursos».

\section{EL CONTROL DE EMISIONES: OBJETIVOS INSUFICIENTES DE REDUCCIÓN EN EL TRÁNSITO HACIA UNA ECONOMÍA HIPOCARBÓNICA}

La mitigación de las emisiones de GEI constituye, en efecto, otra de las acciones prioritarias para avanzar hacia un modelo de crecimiento económico hipocarbónico y circular. Para encauzar la senda hacia este objetivo, la Comisión Europea adoptó en 2011 la hoja de ruta Hacia una economía hipocarbónica competitiva en 2050, que complementa así la iniciativa emblemática para una Europa eficiente en el uso de los recursos. Este documento estratégico establece las actuaciones que permitirían a la UE reducir sus emisiones entre un 80 y un 95\% para 2050, con respecto a los niveles de 1990 y en la línea de las recomendaciones del IPCC para contener el aumento de la temperatura global por debajo de los $2{ }^{\circ} \mathrm{C}$. Este objetivo ha quedado definitivamente consensuado por el acuerdo alcanzado por la comunidad internacional en la Conferencia de las Partes (COP) 21 en París ${ }^{48}$. La hoja de ruta identifica también objetivos intermedios de reducción de emisiones, en concreto del $40 \%$ para 2030 y del $60 \%$ para 2040. Su realización progresiva permitirá valorar si la UE está en vías de lograr el objetivo último de convertirse en una economía hipocarbónica competitiva para 2050. Identifica, asimismo, necesidades de inversión y medidas específicas para los principales sectores responsables de las emisiones, como son el transporte, la energía, la industria, los edificios y la agricultura ${ }^{49}$.

Como prioridad a corto plazo, la hoja de ruta establece la consecución de los objetivos establecidos en el Paquete Clima y Energía 2020. Conforme a este marco de actuación contra el cambio climático, adoptado en diciembre de 2008, la UE se ha comprometido a reducir sus emisiones de GEI en un $20 \%$ con respecto a los niveles de 1990, en el período 2013-2020. Asimismo, promueve el incremento del uso de energías renovables hasta un $20 \%$ en este

48 NACIONES UNIDAS, CONVENCIÓN MARCO SOBRE EL CAMBIO CLIMÁTICO, Aprobación del Acuerdo de París, FCCC/CP/2015/L.9, de 12 de diciembre de 2015, disponible en http://unfccc.int/resource/docs/2015/cop21/spa/109s. pdf (consultado por última vez el 20.09.2016).

49 La Hoja de Ruta de la Energía para 2050, el Libro Blanco de Transporte (COM(2011) 144 final, 28.3. 2011) y el Plan de Eficiencia Energética (COM (2011) 109 final, 8.3.2011), constituyen también marcos estratégicos relevantes en el contexto de los esfuerzos de reducción de emisiones en la UE. 
mismo período y el aumento de la eficiencia energética en un $20 \%{ }^{50}$. Desde el punto vista financiero, la UE se dispone a destinar el $20 \%$ de su presupuesto anual a impulsar las medidas necesarias para alcanzar estas metas de sostenibilidad entre 2014 y $2020^{51}$.

Según estimaciones recientes, la UE está muy cerca de alcanzar el objetivo de reducción de emisiones en un 20\% para 2020. Este logro de mitigación se añadiría al conseguido por la UE en el primer mandato obligatorio del Protocolo de Kioto (2008-2012), en el que la reducción de emisiones fue de un $12 \%$ con respecto a 1990 , esto es, superior al $8 \%$ al que se comprometieron conjuntamente, como UE, los 15 Estados miembros que ratificaron el Protocolo en $2001^{52}$. A la luz de estos datos y tendencias, puede afirmarse que la UE viene realizando en los últimos años importantes avances en lo que supone el proceso de disociar las emisiones contaminantes del crecimiento económico. En concreto, un último informe de la Agencia Europea de Medio Ambiente estima en un 19\% la reducción de emisiones de GEI en la UE en el período 1990-2013, a pesar de que en el mismo período la población en el conjunto de los Estados miembros aumentó un promedio del $6 \%$ y la producción económica experimentó una expansión del $45 \%{ }^{53}$. Ahora bien, las medidas de mitigación adoptadas a nivel de la UE no han sido el único factor que ha

50 COMISIÓN EUROPEA, «Paquete de medidas sobre clima y energía hasta 2020». Toda la información sobre las acciones y normativa aplicable está disponible en http:// ec.europa.eu/clima/policies/strategies/2020/index_es.htm (consultado por última vez el 20.09.2016). Sobre la abundante bibliografía al respecto, véase, entre otros, Sebastian OBERTHÜR y Marc PALLEMAERTS (eds.), The new climate policies of the European Union. Internal legislation and climate diplomacy, Brussels University Press, Bruselas, 2010; María del Pilar BUENO RUBIAL, «La construcción de políticas climáticas europeas y su internacionalización: desafíos pasados, actuales y futuros hacia 2020», Cuadernos Europeos de Deusto, núm. 51, 2014, pp. 123-153.

51 Sonja van RENSSEN, «New: the EU budget. It has never been so green», European Energy Review, 23 de febrero de 2012, disponible en http:/www.europaeum.org/ europaeum/?q=node/1633 (consultado por última vez el 20.09.2016); COMISION EUROPEA, Multiannual Financial Framework 2014-2020 and EU Budget 2014. The Figures, Oficina de Publicaciones Oficiales de la Unión Europea, Luxemburgo, 2013, pp. 7-13.

52 Sobre estos logros de reducción, véase COMISION EUROPEA, «Progress towards achieving the Kyoto and EU 2020 Objectives», COM (2014) 689 final, 28.10.2014, pp. 8-12.

53 AGENCIA EUROPEA DE MEDIO AMBIENTE, «European Union emission inventory report 1990-2013 under the UNECE Convention on Long-range Transboundary Air Pollution (LRTAP), Technical Report 8/2015, pp. 9-14, disponible en 
permitido este descenso de emisiones, ya que la reestructuración industrial de los nuevos Estados miembros del Este de Europa y la crisis económica que se instala en la Eurozona a partir de 2008 han contribuido también a estos resultados.

Con respecto a las energías renovables, se observan igualmente importantes progresos en los últimos años, por lo que, de continuar esta tendencia, la UE podría alcanzar también el objetivo del $20 \%$ en el uso de estas fuentes alternativas para 2020. En la misma línea, la plena implementación de los planes nacionales de acción en eficiencia energética permitiría a la UE la consecución del objetivo del $20 \%$ de aumento ${ }^{54}$. Por tanto, puede afirmarse también con respecto a estos objetivos que la UE está en la senda de poder disociar el uso energético de los resultados económicos para 2020.

Sin embargo, a pesar de estas perspectivas que apuntan al logro de las metas de sostenibilidad del paquete 2020, lo cierto es que la UE sigue siendo altamente dependiente de las energías fósiles, que son las responsables del $80 \%$ de sus emisiones, y parece que lo seguirá siendo en los próximos años ${ }^{55}$. De no revertir esta tendencia en el mix energético, la UE no podrá conseguir sus objetivos de reducción para 2050. En efecto, según estimaciones de la propia Comisión, la efectiva implementación del paquete 2020 podría conducir a una reducción del $32 \%$ para 2030 , frente al $40 \%$ previsto por la hoja de ruta $^{56}$. Con el propósito de reconducir la plena realización de este objetivo intermedio, la Comisión propuso en enero de 2014 un nuevo Paquete Clima y Energía para 2030, aplicable a partir de 2021. Rebajando el nivel de ambición de la propuesta inicial de la Comisión, el Consejo aprobó el nuevo paquete de medidas en octubre de $2014^{57}$.

http://www.eea.europa.eu/publications/lrtap-emission-inventory-report (consultado por última vez el 20.09.2016).

54 AGENCIA EUROPEA DE MEDIO AMBIENTE, «Trends and projections in Europe 2015. Tracking progress towards Europe's climate and energy targets», EEA Report 4/ 2015, pp. 17 y 48-55, disponible en http://www.eea.europa.eu/publications/ trends-and-projections-in-europe-2015 (consultado por última vez el 20.09.2016). AGENCIA EUROPEA DE MEDIO AMBIENTE, "Final energy consumption by sector. Indicator assessment, data and maps», disponible en http:/www.eea.europa.eu/ data-and-maps/indicators/final-energy-consumption-by-sector-9/assessment (consultado por última vez el 20.09.2016); Aurelia MANÉ́ ESTRADA, «La hoja de ruta hacia la creación de baronías energéticas europeas», OIKONOMICS, núm. 3, 2015, pp. 36-44.

56 AGENCIA EUROPEA DE MEDIO AMBIENTE, op. cit., nota 54, pp. 24-25.

57 COMISIÓN EUROPEA, «Marco sobre clima y energía para 2030», disponible en http://ec.europa.eu/clima/policies/strategies/2030/index_es.htm (consultado por última vez el 20.09.2016) 
Los objetivos intermedios que guiarán conforme al nuevo marco la política contra el cambio climático de la UE son los siguientes:

- Un 40\% de reducción de emisiones de GEI con respecto a los niveles de 1990.

- Una utilización de al menos un 27\% de energías renovables para el conjunto de la UE.

- Un aumento de al menos un $27 \%$ en eficiencia energética para el conjunto de la UE.

Es indudable que la adopción de este nuevo marco de actuación constituye una señal positiva en términos de acuerdo político entre los Estados miembros y, al mismo tiempo, de liderazgo de la UE, al adoptarse un año antes de la COP 21 de París, en la que la comunidad internacional acordó nuevos compromisos para el período post-2020. Sin embargo, el nuevo paquete de medidas adolece de debilidades y carencias que, de no superarse, impedirán a la UE alcanzar sus objetivos de transformarse en una economía hipocarbónica para 2050, como así lo evidencian estudios y datos de algunos expertos y organismos.

En primer lugar, el objetivo de recortar el $40 \%$ de las emisiones es considerado, en sí mismo, insuficiente como meta de reducción, no obstante el refuerzo de las acciones e instrumentos que se contemplan para conseguirlo. Entre ellos, el régimen de comercio de emisiones, que seguirá siendo el mecanismo principal de mitigación de $\mathrm{GEI}^{58}$. A través de este instrumento, se espera que las instalaciones de los sectores industriales incluidos reduzcan en un $43 \%$ sus emisiones con respecto a los niveles de 2005. Para conseguirlo, se ha previsto la reforma del mecanismo, por la que, entre otros aspectos, se incrementará la reducción anual de emisiones del 1,74\% actual al 2,2\% a partir de 2021 y se creará, en 2018, una Reserva de Estabilidad del Mercado, con la que se pretende reforzar el sistema frente a excedentes de derechos de emisión

58 Directiva 2003/87/CE de 13 de octubre de 2003 (DO L 275, de 25 de octubre de 2003, p. 32), modificada por la Directiva 2009/29/CE de 23 de abril de 2009 (DO L140, de 5 de junio de 2009, p. 63). Desde el inicio de su tercera fase de aplicación en 2013, este mecanismo establece límites máximos de emisión anual de GEI a nivel de la UE para los sectores incluidos (refinerías, eléctricas, fabricantes de pastas de papel, vidrio, cemento, cerámicas y aerolíneas comerciales), ofreciendo a las instalaciones de los sectores incluidos la posibilidad de vender y comprar permisos de emisión en el mercado, incentivando al mismo tiempo las inversiones en tecnologías y energías limpias. 
y desequilibrios entre la oferta y la demanda de los mismos ${ }^{59}$. Otra acción complementaria clave para encauzar la industria europea en la transición hacia una economía hipocarbónica será la Directiva sobre Emisiones Industriales, que establece también requerimientos sobre control de emisiones y residuos para unas 50000 instalaciones industriales de gran tamaño ${ }^{60}$. Igualmente, para los sectores no incluidos en el mercado de emisiones, como el transporte, salvo el aéreo, la agricultura y los edificios, se contempla también un nuevo esfuerzo de reducción del 30\% con respecto a los niveles de 2005, que habrá de distribuirse entre los Estados miembros conforme a su PIB. Con todo, aunque se lograra el $40 \%$ de recorte de emisiones para 2030, esta reducción no permitiría a la UE alcanzar el objetivo mínimo del $80 \%$ en 2050 . Con esta perspectiva como telón de fondo, algunos estudios estiman que la UE debería fijarse el objetivo vinculante del 55\% para 2030, lo que podría conseguir de continuar con el ritmo anual del $2 \%$ de reducción de los últimos años. De hecho, de mantener esta tendencia, en 2020 no estaría tan lejos del 30\%, incluso sin adoptar medidas adicionales ${ }^{61}$. Además, la reducción del $55 \%$ permitiría a la UE, no sólo alcanzar el objetivo máximo del $95 \%$ en 2050, sino contribuir de forma más equitativa a los esfuerzos globales de mitigación ${ }^{62}$.

59 COMISIÓN EUROPEA, «Propuesta de Directiva del Parlamento Europeo y del Consejo por la que se modifica la Directiva 2003/87/CE para intensificar las reducciones rentables de emisiones y facilitar las inversiones tecnológicas hipocarbónicas», COM (2015) 337 final, 17.7.2015. La Reserva de Estabilidad del Mercado se pondrá en funcionamiento en enero de 2019, según se establece en la Decisión UE 2015/1814 del Parlamento Europeo y del Consejo relativa al establecimiento y funcionamiento de una reserva de estabilidad del mercado para el comercio de derechos de emisión de gases de efecto invernadero en la Unión, y por la que se modifica la Directiva 2003/87/CE (DO L 264, de 9 de octubre de 2015, p. 1).

60 Directiva 2010/75/UE de 24 de noviembre de 2010 (DO L 334, de 17 de diciembre de 2010, p. 17).

61 Simon BULLOCK, Mike CHILDS y Asad REHMAN, How politicians' inaction is ramping up the risk of dangerous climate change, Friends of the Earth (EWNI), 2011, pp.16-19; Niklas HÖHNE et al., «The next step in Europe's climate action: setting targets for 2030", ECOFYS Policy Brief, 2013, pp. 1-9, p. 2, disponible en http:// ec.europa.eu/clima/consultations/docs/0020/organisation/ecofys_en.pdf (consultado por última vez el 20.09.2016); Claudio ARANZADI, «UE 2030: objetivo clima y energía», Política Exterior, vol. 29, núm. 163, 2015, pp. 46-53.

62 Charles HEAPS, Peter ERICKSON, Sivan KARTHA y Eric KEMP-BENEDICT, Europe's share of the climate challenge. Domestic action and international obligations to protect the planet, 2009, Stockholm Environment Institute, 2009, pp. 43-48. 
Con relación a las energías renovables, el objetivo del $27 \%$ se establece para el conjunto de la UE y no para cada Estado, a diferencia del paquete 2020. Esta falta de objetivo vinculante por país es considerado un retroceso, ya que deja aún más vía libre a los Estados miembros para decidir sobre su mix energético o seguir invirtiendo en alternativas no convencionales, como el gas de esquisto, ampliamente cuestionadas por su impacto medioambiental. En cualquier caso, la cifra del $27 \%$ es considerada también insuficiente, alejada del 35\% que algunas voces sugieren para consolidar el camino que están abriendo ya algunos Estados miembros al apostar por las energías renovables con políticas e incentivos ad hoc. Alemania, por ejemplo, ha conseguido en pocos años reducir los costes de las instalaciones eólicas y solares, al punto que en estos momentos resultan entre un 30\% y 50\% más baratas que las plantas de energía nuclear, así como menos costosas también que los complejos productores de gas y carbón en el Reino Unido. Alrededor del 25\% de la producción eléctrica alemana proviene actualmente de fuentes renovables, constituyendo una de las redes de electricidad más estables del mundo, desde la que, además, se exporta energía a los Estados vecinos ${ }^{63}$.

Por tanto, dado que la producción y el consumo de energía procedente de los combustibles fósiles son los causantes de la mayoría de las emisiones de GEI, la UE necesitaría aspirar a un objetivo más ambicioso que el 27\% y asignar porcentajes vinculantes por Estados miembros, si desea alcanzar los objetivos fijados para 2050 en materia de clima y energía ${ }^{64}$.

Con respecto a la eficiencia energética, la meta del $27 \%$ de incremento también se establece a nivel europeo, al igual que en el paquete 2020, y con carácter no vinculante. Este porcentaje también se considera bajo y no alineado con la necesidad de reducir la dependencia energética y transitar hacia una economía hipocarbónica para 2050. Algunas prospectivas avalan, por ello, que con medidas vinculantes más ambiciosas de reducción del consumo energético, se podría conseguir hasta un $40 \%$ de incremento de eficiencia energética y un ahorro directo de 250000 millones de euros para el año $2030^{65}$.

63 Rainer BAAKE et al., 12 Insights on Germany's energiewende, Agora Energiewende, febrero 2013, disponible en https://www.agora-energiewende.de/en/die-energiewende/12-insights-of-germanys-energiewende/ (consultado por última vez el 20.09.2016).

64 «Análisis del paquete clima y energía 2030», Foro Transición Energética y Cambio Climático, 14 de noviembre de 2014, disponible en http://www.transicionenergeticaycc.org/web/es/foro/post/Analisis-del-Paquete-Clima-y-Energia-2030/ (consultado por última vez el 20.09.2016).

65 Edith MOLENBROEK y Kornelis BLOK, Saving energy. Bringing down Europe's energy prices for 2020 and beyond, ECOFYS, 2013, pp. 1-16, pp. 13-14, disponible en http:// 
Consecuentemente con todo lo anterior, puede concluirse que, con respecto a la reducción de emisiones como apuesta prioritaria para una economía competitiva e hipocarbónica, la UE está en vías de alcanzar los objetivos para 2020, pero no así los establecidos para 2030 y 2050. Ello implica la necesidad de revisar al alza las metas de mitigación de GEI y el uso de energía para transitar de forma creíble hacia una sociedad europea eficiente en el uso de recursos y de baja emisión de carbono.

Con todo, aún revisada y reforzada, la estrategia interna resultará inefectiva si no se aborda de forma simultánea y consistente la dimensión externa del desafío que comporta la escasez de recursos naturales.

\section{LA DIMENSIÓN EXTERIOR DE LA AGENDA EUROPEA: LA FALTA DE UNA ESTRATEGIA COHERENTE CON EL DESARROLLO SOSTENIBLE}

La iniciativa emblemática «Una Europa que utilice eficazmente los recursos» reconoce que la gestión eficiente de recursos constituye una preocupación de interés global, que debe abordarse a través de la cooperación internacional con socios clave, especialmente economías emergentes con altos niveles de consumo. La UE intenta jugar un papel de liderazgo internacional potenciando la gestión eficiente de recursos como componente esencial de su contribución al desarrollo sostenible. Sin embargo, este papel es ampliamente cuestionado debido a las incoherencias y contradicciones entre las prioridades de la UE y sus propias acciones. Para contribuir a mejorar la gobernanza global de forma creíble, la UE deberá formular una estrategia de acción exterior más comprensiva, coherente con las medidas adoptadas en su ámbito interno y que garantice de forma efectiva el uso eficiente de recursos como elemento clave del desarrollo sostenible.

\section{EL DESARROLLO SOSTENIBLE COMO MARCO JURÍDICO DE LA COOPERACIÓN INTERNACIONAL PARA EL USO EFICIENTE DE RECURSOS}

La pobreza, el desarrollo y el medio ambiente están estrechamente relacionados. Las economías más pobres son las que más dependen directamente de los recursos naturales para el sustento diario de sus comunidades $y$,

www.assoelettrica.it/wp-content/uploads/2013/03/saving_energy_study_feb2013.pdf (consultado por última vez el 20.09.2016). 
al mismo tiempo, las más vulnerables a los envites del cambio climático. La protección y gestión eficiente de recursos naturales constituye, por ello, un componente esencial de la acción internacional de la UE para la promoción del desarrollo sostenible como modelo de cooperación que toma en cuenta las dimensiones económicas, sociales y medioambientales del desarrollo ${ }^{66}$. El art. 21.2d) del Tratado de la Unión Europea (TUE) establece el desarrollo sostenible como objetivo de la acción exterior de la UE, pero en realidad, constituye un objetivo horizontal que promover y garantizar a largo plazo en todas sus políticas, como así se prevé en el art. 3.3 del TUE. La Estrategia para el Desarrollo Sostenible (2001), tras su revisión en 2009, proporciona la visión a largo plazo y el marco de actuación para las políticas de la UE hasta $2050^{67}$.

La UE ha intentado jugar un papel de liderazgo en la promoción internacional del desarrollo sostenible, a través de sus propias iniciativas y por medio también de los compromisos asumidos en los foros multilaterales, como Río $+20^{68}$, el Protocolo de Nagoya sobre el Acceso a Recursos Genéticos y la Distribución Justa de Beneficios ${ }^{69}$, la COP 12 de la Convención sobre Diversidad Biológica ${ }^{70}$ o el proceso que condujo a la adopción de la Agenda 2030 para el Desarrollo Sostenible ${ }^{71}$. Entre las iniciativas propias, la UE intenta promover niveles altos de protección medioambiental y uso sostenible de recursos natura-

66 El concepto de «desarrollo sostenible» aparece definido por primera vez en el Informe Brundtland («Nuestro Futuro Común», 1987), preparado por la Comisión Mundial de Medio Ambiente y Desarrollo de Naciones Unidas. Disponible en https://en.wikisource.org/wiki/Brundtland_Report (consultado por última vez el 20.09.2016). COMISIÓN EUROPEA, «Incorporación del desarrollo sostenible en las políticas de la Unión Europea: informe de 2009 sobre la estrategia de la UE para el desarrollo sostenible», COM (2009) 400 final, 24.7.2009.

68 CONSEJO DE LA UNIÓN EUROPEA, "Conclusions on Rio+20: outcome and follow-up to the UNCSD 2012 summit», 25 de octubre de 2012, disponible en http://www.consilium.europa.eu/uedocs/cms_data/docs/pressdata/en/envir/133219. pdf (consultado por última vez el 20.09.2016).

69 Incorporado al ordenamiento jurídico de la UE a través de la Decisión 2014/283/UE de 14 de abril de 2014 (DO L 150, de 20 de mayo de 2014, p. 231).

70 CONSEJO DE LA UNIÓN EUROPEA, «Convention on biological diversity. Council conclusions", 12 de junio de 2014, disponible en http://www.consilium.europa. eu/uedocs/cms_data/docs/pressdata/en/envir/143185.pdf (consultado por última vez el 20.09.2016).

71 COMISIÓN EUROPEA, «La Comisión Europea acoge favorablemente la nueva Agenda de Desarrollo Sostenible de las Naciones Unidas para 2030», 25 de septiembre de 2015, disponible en http://europa.eu/rapid/press-release_IP-15-5708_es.htm (consultado por última vez el 20.09.2016). 
les a través de sus programas de cooperación al desarrollo. Estos requerimientos aparecen claramente recogidos en algunos de los instrumentos geográficos de financiación externa de la política europea de cooperación al desarrollo, a saber, el Instrumento de Cooperación al Desarrollo ${ }^{72}$, el Instrumento Europeo de la Política de Vecindad ${ }^{73}$ y el Fondo Europeo de Desarrollo ${ }^{74}$.

Un parámetro esencial de la acción europea en la promoción del desarrollo sostenible es la coherencia de las políticas para el desarrollo (CPD). Introducida como compromiso político en el Consenso Europeo sobre el Desarrollo $(2005)^{75}$, la CPD se ha transformado en una obligación jurídica de la UE, tal como se establece actualmente en el art. 208 del Tratado de Funcionamiento de la Unión Europea (TFUE). Esta disposición establece en el segundo párrafo de su primer apartado que «La Unión tendrá en cuenta los objetivos para el desarrollo al aplicar las políticas que puedan afectar a los países en desarrollo». Esta obligación también se extiende a los Estados miembros, ya que la política de cooperación al desarrollo es un ámbito de competencia compartida con la UE, como así se establece en el art. 4.4 del TFUE y en el propio art. 208.1. A partir de 2009, la CPD se aplica prioritariamente a cinco áreas de actuación europea: comercio y financiación económica, cambio climático, seguridad alimentaria global, migración y seguridad ${ }^{76}$. La Comisión Europea es la encargada de publicar cada dos años un informe sobre los progresos de sinergia coherente entre estas políticas y la cooperación al desarrollo ${ }^{77}$.

La CPD es considerada, por tanto, una herramienta fundamental para integrar consistentemente las dimensiones económica, social y medioambiental del desarrollo sostenible en todas las etapas de decisión y acción a nivel interno e internacional. El compromiso de garantizar la coherencia de las distintas políticas que inciden en el desarrollo de países terceros es también un

72 Art. 2, sobre «Objetivos y criterios para acceder a la financiación», del Reglamento UE 233/2014 de 11 de marzo de 2014 (DO L 77, de 15 de marzo de 2014, p.27).

73 Art. 1, sobre «Objeto y objetivos», del Reglamento UE 232/2014 de 11 de marzo de 2014 (DO L 77, de 15 de marzo de 2014, p. 27).

74 Art. 1, sobre «Objetivos y criterios para acceder a la financiación», del Reglamento UE 2015/323 de 2 de marzo de 2015 (DO L 58, de 3 de marzo de 2015, p. 17).

75 Véase la declaración conjunta del Consejo y de los representantes de los Gobiernos de los Estados miembros reunidos en el seno del Consejo, del Parlamento Europeo y de la Comisión sobre la política de desarrollo de la Unión Europea titulada «El consenso europeo sobre el desarrollo», p. 2, apartado 9 (DO C 46, de 24 de febrero de 2006, p. 1).

76 CONSEJO DE LA UNIÓN EUROPEA, "Council conclusions on policy coherence for development», 16079/09, 18 de noviembre de 2009.

77 El último fue publicado en 2015. Véase COMISIÓN EUROPEA, Policy coherence for development. 2015 EU report, SWD (2015) 159 final de 3 de agosto de 2015. 
componente esencial del enfoque de la Organización para la Cooperación y el Desarrollo Económicos (OCDE) sobre el desarrollo sostenible ${ }^{78}$, habiendo sido incluido igualmente como objetivo específico en la Agenda 2030 para el Desarrollo Sostenible ${ }^{79}$. En consecuencia, más allá de la UE, la CPD se ha transformado en un compromiso universal para garantizar el desarrollo sostenible por todos los actores implicados y en todos los niveles de actuación.

En su comunicación "Una vida digna para todos. De la visión a la acción colectiva», la Comisión Europea expresaba el compromiso de la UE de fomentar la CPD, al tiempo que emplazaba a los países desarrollados y subdesarrollados a promover también la coherencia de políticas como contribución a la implementación efectiva de la agenda post-2015 ${ }^{80}$. Como objetivo más ambicioso, la Comisión Europea y algunos Estados miembros, como Holanda y Reino Unido, propusieron la «coherencia de políticas para el desarrollo sostenible», durante las negociaciones en el grupo de trabajo de Naciones Unidas sobre los objetivos de desarrollo sostenible ${ }^{81}$. Este concepto pone el énfasis en un enfoque más amplio que integre de forma más coherente las tres dimensiones del desarrollo sostenible. El término también aparece mencionado en las Conclusiones del Consejo sobre una Agenda Transformadora Post-2015, como estrategia conducente al éxito del nuevo marco de desarrollo ${ }^{82}$. Sin embargo, el concepto de "coherencia de políticas para el desarrollo sostenible» no ha sido adoptado a nivel global, por lo que queda por ver si coexistirá por separado de la CPD o si ambos conceptos acabarán integrándose a través de mecanismos institucionales que puedan crearse para su puesta en práctica ${ }^{83}$.

78 OCDE, Better policies for development: policy coherence and illicit financial flows, 2014, p.16, disponible en http://www.oecd.org/pcd/Better-Policies-for-Development-2014. pdf (consultado por última vez el 20.09.2016).

79 Objetivo 17, meta 14. Véase http://www.un.org/sustainabledevelopment/es/2015/09/ la-asamblea-general-adopta-la-agenda-2030-para-el-desarrollo-sostenible/ (consultado por última vez el 20.09.2016).

80 COM (2014) 335 final, 2.2.2014. En particular, punto 5: «Un nuevo partenariado global».

81 Anna KNOLL, «Bringing Policy Coherence for Development into the Post-2015 Agenda-Challenges and Prospects», European Centre for Development Policy Management (ECDPM) Discussion Paper, núm. 163, 2014, p. 5, disponible en http://ecdpm.org/ wp-content/uploads/DP-163-Policy-Coherence-for-Development-Post-2015-Agenda-Challenges-Prospects-2014.pdf (consultado por última vez el 20.09.2016).

82 CONSEJO DE LA UNIÓN EUROPEA, «Council Conclusion on a transformative post-2015 agenda», 16 diciembre 2014, p. 5, apartado 29.

83 CONCORD, "Operationalising policy coherence for development», Spotlight Report 2015, p. 4, disponible en http://library.concordeurope.org/record/1634/files/ DEEEP-REPORT-2016-008.pdf (consultado por última vez el 20.09.2016). 
Existe, por tanto, un mandato jurídico claro y una evidente voluntad política por parte de la UE y los Estados miembros de contribuir al desarrollo sostenible a través de la coherencia de políticas que inciden en sus diferentes dimensiones. Sin embargo, el modelo de desarrollo económico de la UE, asentado todavía en un alto consumo energético y de recursos naturales, genera consecuencias negativas para los países en desarrollo, precisamente por la falta de coherencia entre las diferentes políticas. En consecuencia, puede afirmarse que, a pesar de los mecanismos institucionales e instrumentos adoptados para su implementación eficaz, la CPD sigue siendo una aspiración que se diluye cuando se desciende a la aplicación práctica de las políticas de la UE.

\section{INCOHERENCIAS E INSUFICIENCIAS EN LA ACCIÓN EXTERIOR DE LA UE}

En efecto, el papel de liderazgo que la UE pretende ejercer en la promoción del desarrollo sostenible queda en entredicho por las numerosas contradicciones entre sus objetivos y sus propias acciones. En concreto, se observan importantes incoherencias entre el objetivo de desarrollo sostenible y las actuaciones de lucha contra el cambio climático y de gestión de recursos naturales ${ }^{84}$.

Un claro ejemplo de incoherencia entre la cooperación al desarrollo sostenible y la ayuda a los países pobres en la adaptación al cambio climático, especialmente en lo que respecta al uso eficiente de recursos naturales, es la política de biocombustibles de la UE. La directiva sobre energías renovables establece que los Estados miembros deberán introducir en los transportes un $10 \%$ de uso de biocombustibles para 202085. Las subvenciones que los Estados miembros están concediendo para promover el uso de biocombustibles

84 Frank BARRY, Michael KING y Alan MATTHEWS, «Policy coherence for development: five challenges", Institute for International and Integration Studies (IIIS) Discussion Paper,núm. 335, 2010, pp.6-16, disponible en https://www.tcd.ie/iiis/ documents/discussion/pdfs/iiisdp335.pdf (consultado por última vez el 20.09.2016); Marta LATEK, «Policy coherence for development: still some way to go», European Parliament Research Service (EPRS) Briefing, 2015, p. 2, disponible en http://www.europarl. europa.eu/RegData/etudes/BRIE/2015/556996/EPRS_BRI(2015)556996_EN.pdf (consultado por última vez el 20.09.2016); Maurizio CARBONE, «The European Union and policy coherence for development: high on mechanisms, low on achievements", EU policy coherence for development: the challenge of sustainability, Workshop, European Parliament Directore-Generale for External Policies, 2016, pp. 14-21, disponible en http://www.europarl.europa.eu/RegData/etudes/STUD/2016/535022/EXPO_ STU(2016)535022_EN.pdf (consultado por última vez el 20.09.2016).

85 Directiva 2009/28/CE de 23 de abril de 2009 (DO L 140, de 5 de junio de 2009, p. 16). 
en sus propios mercados ha provocado un aumento de las importaciones de este tipo de energías procedentes de África, Asia y Latinoamérica, lo que ha acarreado consecuencias negativas para algunos países pobres de estas regiones. Entre los efectos adversos destacan, por ejemplo, la apropiación de tierras, los cambios en el uso de terrenos, el incremento de emisiones, el aumento de precios de alimentos y el agravamiento de la inseguridad alimentaria ${ }^{86}$. Estos efectos perjudiciales para las economías en desarrollo claramente contradicen el objetivo de la UE de contribuir al uso eficiente de recursos naturales como pilar esencial del desarrollo sostenible.

Otra incoherencia con la pretendida gestión eficiente de recursos en países en desarrollo es la exportación, legal o ilegal, de residuos por parte de la UE. En tanto en cuanto estos países no dispongan de las capacidades y tecnologías adecuadas para convertir estos residuos en recursos o reciclarlos, estos traslados contribuyen a incrementar las emisiones y deteriorar el medioambiente, repercutiendo negativamente en la salud pública ${ }^{87}$. En 2014, la UE modificó el Reglamento UE 1013/2006 sobre traslado de residuos, con el principal objetivo de facilitar la detección de las exportaciones ilegales ${ }^{88}$. Para evitarlas, los Estados miembros están obligados a establecer, antes de enero de 2017, planes nacionales de inspección, donde se fije el número de inspecciones que deben realizarse con tal propósito.

Asimismo, otra inconsistencia con la promoción del desarrollo sostenible reside en la falta de una normativa supranacional que obligue a las empresas europeas que extraen minerales en países en desarrollo a evaluar e informar sobre el impacto medioambiental y socioeconómico de su actividad. En 2014,

86 Demba DIOP et al., Assessing the impact of biofuels production on developing countries from the point of view of Policy Coherence for Development, Final Report, AETS Consortium, febrero 2013, disponible en http://ec.europa.eu/europeaid/sites/devco/files/ study-impact-assesment-biofuels-production-on-development-pcd-201302_en_2. pdf (consultado por última vez el 20.09.2016); Didier BOURGUIGNON, «EU Biofuels Policy. Dealing with Indirect Land Use Change», EPRS Briefing, febrero 2015, disponible en http:/www.europarl.europa.eu/RegData/etudes/BRIE/2015/548993/ EPRS_BRI(2015)548993_REV1_EN.pdf (consultado por última vez el 20.09.2016). Jim BAIRD, Robin CURRY y Paulo CRUZ, «An overview of waste crime, its characteristics, and vulnerability of EU waste sector", Research \& Management, vol. 32, núm. 2, 2014, pp. 97-105; AAVV, Waste Crime-Waste Risks. Gaps in meeting the global waste challenge, United Nations Environment Programme (UNEP), Nairobi y Arendal, 2015.

88 Reglamento UE 660/2014 del Parlamento Europeo y del Consejo de 15 de mayo de 2014, por el que se modifica el Reglamento UE 1013/2006 relativo a los traslados de residuos (DO L 189, de 27 de junio de 2014, p. 135). 
la UE adoptó la Directiva 2014/95/UE de 22 de octubre, relativa a la divulgación de la información no financiera y la diversidad ${ }^{89}$. Esta norma impone el requisito de proporcionar información ambiental y social a las grandes empresas de interés público (bancos, aseguradoras, compañías que cotizan en bolsa, etc.), con más de 500 empleados. Será de aplicación a partir de enero de 2017 a unas 6000 empresas de gran tamaño. Sin embargo, a pesar de representar un paso adelante en términos de transparencia, la nueva regulación se considera insuficiente y escasamente vinculante, ya que no afecta a empresas con menos de 500 trabajadores. Además, deja a las compañías europeas excesiva flexibilidad a la hora de elegir los aspectos sobre los que informar y el marco jurídico, nacional, internacional o europeo a utilizar, por lo que es previsible que conduzca a las mismas insuficiencias observadas en los informes sobre sostenibilidad que actualmente publican algunas empresas voluntariamente ${ }^{90}$.

En el mismo sentido, la ausencia de una normativa europea vinculante sobre las importaciones de minerales procedentes de zonas de conflicto arroja otra fuente de incoherencia con respecto a la gestión eficiente de recursos, el desarrollo sostenible y la propia seguridad internacional. La República Democrática del Congo o la región de los Grandes Lagos aportan ejemplos de cómo la extracción e importación de minerales, y los consiguientes ingresos que reportan a estos países, pueden provocar o agravar los conflictos armados internos. Naciones Unidas y la OCDE han adoptado orientaciones y recomendaciones no vinculantes para las compañías que se abastecen de minerales de zonas de conflicto. Estados Unidos tiene en vigor una normativa vinculante aplicable a los minerales procedentes de una lista de países ${ }^{91}$. Con respecto a la

89 DO L 330, de 15 de noviembre de 2014, p. 1.

90 Tan solo un $10 \%$ de las compañías europeas aportan estos informes, la mayoría de los cuales, en efecto, no contiene información relevante sobre el impacto que sus actividades tienen en los ecosistemas y comunidades locales. CONCORD, «Spotlight on EU policy coherence for development. The real life impact of EU policies on the poor», Report 2013, pp. 47-48, disponible en http://concordeurope.org/wp-content/ uploads/2016/07/PCD-ENG.pdf?1d6b43 (consultado por última vez el 20.09.2016); Jerome CHAPLIER y Filip GREGOR, «Assessment of the new EU Directive on the disclosure of non-financial information by some large companies», European Coalition for Corporate Justice (ECCJ Briefing, mayo 2014, disponible en https://business-humanrights.org/sites/default/files/media/documents/eccj-assessment-eu-non-financial-reporting-may-2104.pdf (consultado por última vez el 20.09.2016).

91 Liam DOWNEY, Eric BONDS y Katerine CLARK, «Natural resource extraction, armed violence, and environmental degradation», Organization \& Environmet, vol. 23, núm. 4, 2010, pp. 417-445, disponible en http://www.ncbi.nlm.nih.gov/pmc/ articles/PMC3169238/ (consultado por última vez el 20.09.2016); Gisela GRIEG- 
UE, el Parlamento Europeo propuso en 2014 la adopción de un Reglamento UE, por el que las empresas europeas estarían obligadas a explicar las medidas adoptadas para evitar riesgos en sus cadenas de suministro y garantizar que sus compras sean legítimas. Por el momento, el proyectado Reglamento sigue en fase de propuesta, a la espera de su adopción definitiva por el Parlamento Europeo y el Consejo ${ }^{92}$.

Estas incoherencias e insuficiencias ponen en evidencia la falta de una interacción efectiva entre las distintas políticas que inciden en el desarrollo sostenible y la gestión eficiente de recursos como pilar fundamental de éste último. Al mismo tiempo, son indicadores de una carencia de mayor calado, como es la ausencia de una estrategia exterior específica de la UE en este ámbito, a diferencia del marco estratégico múltiple existente a nivel interno ${ }^{93}$.

A las incoherencias horizontales entre las diferentes acciones, hay que añadir otra de tipo vertical, como es la falta de una interacción efectiva entre las políticas de cooperación de la UE y las de los Estados miembros. La ausencia de una programación conjunta y de coordinación de la ayuda sigue generando duplicidades y costos adicionales, que merman la efectividad de la ayuda europea ${ }^{94}$.

ER, «Minerals from conflict areas. Existing and new responsible-sourcing initiatives», EPRS Briefing, 11 de febrero de 2014, disponible en http://www.europarl.europa. eu/RegData/bibliotheque/briefing/2014/130680/LDM_BRI(2014)130680_REV1_ EN.pdf (consultado por última vez el 20.09.2016).

92 Véase «Propuesta de Reglamento del Parlamento Europeo y del Consejo por el que se establece un sistema de la Unión para la autocertificación de la diligencia debida en la cadena de suministro de los importadores responsables de estaño, tantalio y wolframio, sus minerales y oro originarios de zonas de conflicto y de alto riesgo», COM (2014) 111 final, 5.3.2014; Peter MALDONADO, «¿Hasta cuándo Europa hará caso omiso de los minerales de sangre?», 11 de abril de 2016, disponible en http://conflictminerals.es/es/hasta-cuando-europa-hara-caso-omiso-de-los-minerales-de-la-muerte/ (consultado por última vez el 20.09.2016).

93 La dimensión del reto que supone la escasez de recursos y la agenda política para abordarlo están poco definidos también a nivel global. Ello contrasta con los objetivos más precisos y los instrumentos más concretos de mitigación de emisiones adoptados en el marco de Naciones Unidas. Véase LEINEN, op.cit., nota 2, p. 52.

94 Alrededor de 800 millones de euros al año. Véase PARLAMENTO EUROPEO, «2013 Report of the EU on the coherence of development policies», A7-0161/2014, 6 de marzo de 2014, p.1; Jesús Ángel FUENTAJADA PASTOR, «La cooperación al desarrollo de la UE», Revista de Derecho de la Unión Europea, núm.9, 2005, pp. 163-196, pp. 167-168; Monika NOGAJ, «The cost of non-Europe in development policy: increasing coordination between EU donors», CoNE 1/2013, EAVA, dis- 
Por tanto, el desarrollo económico y social no resulta sostenible si daña los ecosistemas y la biodiversidad, incrementa las emisiones y la vulnerabilidad a los desastres naturales, agravando con ello la escasez de recursos naturales, la pobreza y la dependencia de la ayuda internacional. Consecuentemente, si la UE desea mantener su legitimidad y credibilidad a nivel global como actor de desarrollo sostenible, deberá potenciar medidas con un enfoque más holístico y consistente entre su acción interna y su actividad internacional. Por el momento, las iniciativas europeas intentan ser más coherentes con el objetivo del desarrollo sostenible, sin vislumbrarse, no obstante, una estrategia exterior específica.

\section{INICIATIVAS Y PROPUESTAS PARA UNA CONTRIBUCIÓN INTERNACIONAL MÁS CONSISTENTE}

La implementación del nuevo marco mundial que representa la Agenda 2030 ofrece a la comunidad internacional la oportunidad de abordar de forma conjunta y coherente los desafíos de la reducción de la pobreza y del desarrollo sostenible. La obligación jurídica y los mecanismos institucionales de que dispone la UE le proporcionan una posición única para liderar la promoción de la CPD, como uno de los objetivos de la Agenda 2030.

$\mathrm{La} \mathrm{CPD}$ es, en efecto, una prioridad para la UE, pero en la práctica deben mejorarse numerosos aspectos para resultar efectiva. Uno de ellos es el mecanismo de evaluación de los impactos que las acciones de la UE tienen en el desarrollo de los países pobres. La experiencia demuestra hasta el momento que pocos informes de evaluación de la Comisión Europea (17 de 177 en el período 2009-2013) han tenido en cuenta el impacto potencial de las distintas medidas de la UE desde la perspectiva de la CPD ${ }^{95}$. En 2014, sólo un 8\% de los informes de impacto de la Comisión tomaban en consideración esta incidencia en términos de desarrollo ${ }^{96}$. Esta deficiencia le ha merecido muchas críticas a la Comisión, al extenderse en sus informes sobre los potenciales

ponible en www.europarl.europa.eu/committees/en/studies.html (consultado por última vez el 20.09.2016); Marta LATEK, «The challenge of coordinating European development policies. Fragmentation, a disaster?», EPRS In-Depth Analysis, enero 2015, disponible en http://www.europarl.europa.eu/RegData/etudes/IDAN/2015/542146/ EPRS_IDA(2015)542146_EN.pdf (consultado por última vez el 20.09.2016); Jan ORBIE y Maurizio CARBONE, "The Europeanisation of development policy», European Politics and Societies, vol.17, núm.1, 2016, pp. 1-11.

95 CONCORD, op.cit., nota 90, p. 19.

96 CONCORD, «The European Commission's better regulation package will it serve poverty eradication and human rights?», Spotlight Report 2015, p. 3, disponible en 
efectos positivos de las iniciativas europeas, mientras ignoraba, sin embargo, las consecuencias económicas y sociales negativas para los países en desarro$1 \mathrm{lo}^{97}$. En esta línea, por ejemplo, la evaluación del impacto sobre el Acuerdo de Libre Comercio e Inversión (TTIP, en sus siglas en inglés) entre la UE y los EEUU prácticamente soslaya los efectos que tendrá en el nivel de pobreza y desigualdad existente en África, así como en las industrias emergentes de este continente. Algunos estudios revelan, sin embargo, que el TTIP generará grandes pérdidas de ingresos y empleos en África y también en Asia ${ }^{98}$.

Con el fin de mejorar precisamente los mecanismos de evaluación de impactos y otros aspectos relativos al proceso de adopción de actos jurídicos, la Comisión adoptó, en mayo de 2015, un nuevo marco de actuaciones bajo el título «Legislar mejor para obtener mejores resultados. Un programa de la $\mathrm{UE}{ }^{99}$. El objetivo principal del nuevo programa es conseguir que las decisiones institucionales y normas jurídicas se adopten de forma más transparente, participativa y simplificada. La iniciativa se aplica a todos los ámbitos de competencia europea, incluyendo todo el ciclo de producción normativa, desde la concepción y planificación hasta la evaluación y ejecución de las políticas y actos jurídicos. Con respecto en concreto a la CPD, se contempla, como uno de los instrumentos de mejora, la evaluación sistemática de los posibles efectos

http://library.concordeurope.org/record/1636/files/DEEEP-REPORT-2016-010.pdf (consultado el 20.09.2016).

97 Frédéric SIMON, «When science meets politics: the EU’s impact assessment review», Euroactiv, 7 de agosto de 2014, disponible en http://www.euractiv.com/section/science-policymaking/linksdossier/when-science-meets-politics-the-eu-s-impact-assessment-review/\#ea-accordion-issues (consultado por última vez el 20.09.2016). Gabriel FELBERMAYR, Benedikt HEID y Sybille LEHWALD, Transatlantic Trade and Investment Partnership: who benefits from a free trade deal?, Bertelsmann Stiftung, 2013, p. 28, disponible en http://www.bfna.org/sites/default/files/TTIP-GED\%20 study\%2017June\%202013.pdf (consultado por última vez el 20.09.2016). COMISIÓN EUROPEA, COM (2015) 215 final, 19.5.2015. Este programa, que sustituye el Plan de Acción «Simplificar y mejorar el marco regulador» de 2003, [COM (2002) 278 final], se complementa con un acuerdo institucional entre el Parlamento Europeo, el Consejo y la Comisión Europea, adoptado el 12 de mayo de 2016 (DO L 123, de 12 de mayo de 2016, p.1), con las directrices para la mejora de la legislación y el programa REFIT de adecuación y eficacia de la reglamentación. Véase Javier GUILLEM CARRAU, «La mejora de los entornos normativos y la complejidad económica: el ajuste regulatorio (REFIT) de la UE», Corts. Anuario de Derecho Parlamentario, núm. 28, 2015, pp. 187-208; Stijn SMISMANS, "Policy evaluation in the EU: the challenges of linking ex ante and ex post appraisal», European Journal of Risk Regulation (EJRR), vol. 6, núm. 1, 2015, pp. 6-26. 
de las diferentes iniciativas en los países en vías de desarrollo. Para responder a esta pretensión, la Comisión adoptó en marzo de 2016 una hoja de ruta sobre la evaluación de la CPD y su adecuación a los objetivos de desarrollo. El documento especifica nuevos criterios y herramientas para mejorar la evaluación de la CPD a lo largo de un período que se extiende hasta el 1 de enero de $2018^{100}$. Es todavía pronto para valorar la efectividad de las nuevas herramientas destinadas a garantizar la CPD, pero, sobre el papel, el nuevo paquete ha sido ya criticado por falta de ambición política y por considerarse insuficiente para promover realmente la protección económica, social y medioambiental en los países más vulnerables ${ }^{101}$.

Con respecto al control de las empresas europeas que extraen minerales y/o que se abastecen de los mismos, provenientes o no de zonas de conflicto, la UE debería extender la obligación de buenas prácticas a todos los recursos naturales, más allá de la normativa existente para algunos de ellos, como la madera y las materias primas ${ }^{102}$. De forma más comprehensiva y en consonancia con los estándares de la OCDE, la nueva regulación establecería la obligación de transparencia y buena diligencia a todos los operadores europeos que se abastezcan de recursos en los países pobres. Esta obligación incluiría la necesidad de someterse a una auditoría externa, así como a un informe público sobre los esfuerzos de diligencia debida y, eventualmente, a un mecanismo de sanciones en caso de incumplimiento ${ }^{103}$.

Como potencia comercial, la UE está en una posición prominente para contribuir también a la configuración de un mercado mundial de bienes respetuosos con el medio ambiente, accesible en condiciones de equidad a todas las economías y en el que la propia UE pueda garantizarse el suministro de materias primas y recursos esenciales. Como ejemplo de acciones concretas, la UE podría apoyar la iniciativa sobre la Cooperación Económica Asia Pacífico, que está intentando precisamente impulsar en la región el comercio de productos respetuosos con el medio ambiente, o los proyectos de uso de energías

100 COMISION EUROPEA, «Evaluation and fitness check (FC) Roadmap. Evaluation of EU Policy Coherence for Development», disponible en http://ec.europa.eu/ smart-regulation/roadmaps/docs/2018_devco_001_evaluation_pcd_en.pdf (consultado por última vez el 20.09.2016).

101 CONCORD, op. cit., nota 96, pp. 2-7.

102 Respectivamente, Reglamento UE 995/2010 de 20 de octubre de 2010 por el que se establecen las obligaciones de los agentes que comercializan madera y productos de la madera (DO L 295, de 12 de noviembre de 2010, p. 23) y La iniciativa de las materias primas: cubrir las necesidades fundamentales de Europa para generar crecimiento y empleo, COM (2008) 699 final, 4.11.2008.

103 GRIEGER, op. cit., nota 91, p. 7. 
renovables en la región del Mediterráneo (MENA), así como contribuir a reanudar las negociaciones en el seno de la Organización Mundial del Comercio en todos los sectores relativos a recursos ${ }^{104}$.

Finalmente, la creación dentro de la propia UE de un grupo de trabajo específico sobre gestión eficiente de recursos naturales, compuesto de representantes del Consejo, del Servicio Europeo de Acción Exterior, de la Comisión Europea y del Parlamento Europeo, bajo la supervisión de la Alta Representante de la UE para la Política Exterior y de Seguridad, podría proporcionar una mayor coherencia a la acción interna y externa de la UE en este ámbito. Una de sus primeras y principales tareas sería redactar un documento conjunto, que incorpore una visión más holística sobre este desafío, identificando los instrumentos y los medios financieros necesarios para abordarlo. Este trabajo conjunto podría servir de base para formular una única estrategia general, con líneas concretas de acción en materia de recursos, que pudiera ser posteriormente desarrollada a través de estrategias más específicas para los distintos recursos clave.

\section{CONCLUSIONES}

El acceso seguro a los recursos se ha transformado para la UE en una prioridad económica de primer nivel, debido a su alta dependencia de las importaciones de materias primas y energía. Para hacer frente a este desafío, la UE ha iniciado en la última década la transición hacia un modelo de crecimiento económico más sostenible y circular. Así lo evidencian los múltiples marcos estratégicos y acciones específicas adoptados en sectores clave como las materias primas, la producción y el consumo, los residuos o el control de emisiones contaminantes, entre otros. Reflejo de la Estrategia Europa 2020, la implementación de las medidas en marcha, así como de otras tantas cuya adopción está prevista para los próximos años, implica a las autoridades nacionales, regionales y locales, al igual que a los agentes económicos, consumidores y ciudadanos en general, en lo que aspira a convertirse en un nuevo patrón de gobernanza más eficiente en el uso de recursos.

El análisis realizado y los datos aportados demuestran que pautas más sostenibles en el uso de recursos empiezan a implantarse progresivamente en

104 Annika AHTONEN y Andrea FRONTINI, «Meeting Europe's resource challenge within and beyond EU borders», Notre Europe, Policy Paper, no 78, 2013, p.6, disponible en http://www.institutdelors.eu/media/ressourceschallenge-ahtonenfrontini-ne-jdi-march13.pdf?pdf=ok (consultado por última vez el 20.09.2016). 
la UE. Así lo confirma, por ejemplo, el menor consumo de materiales registrado en el período 2002-2014, acompañado, no obstante, de un incremento de productividad, lo que evidencia la disociación paulatina del consumo de recursos del crecimiento económico. En la misma línea, los progresos en términos de ecoinnovación, gestión de residuos y comportamientos de consumo más sostenible constituyen indicadores del tránsito iniciado hacia el nuevo paradigma económico.

Sin embargo, a pesar de los avances observados, queda todavía mucho por hacer, como así lo reconocen las propias instancias europeas (Comisión y Agencia Europea de Medio Ambiente) para alcanzar la visión de la UE como una economía que en 2050 gestionará todos los recursos de forma sostenible. En este sentido, existe todavía amplio margen para mejorar, por ejemplo, la elaboración de productos que consuman menos recursos y contaminen menos, o los procesos de reciclado, acción clave esta última para reducir la inseguridad energética y mitigar los efectos económicos de la volatilidad de precios. En este mismo contexto, queda por desarrollar un mercado europeo de productos secundarios, así como implementar plenamente la estrategia de ecoinnovación e impulsar la gestión y el reciclado de residuos. En general, los progresos son lentos y los resultados escasos, lo que es debido principalmente a una insuficiente y asimétrica implementación por parte de los Estados miembros.

Por otra parte, este estudio revela que los diversos marcos estratégicos y las múltiples iniciativas de la UE, aunque convergen en promover el uso eficiente de recursos y la protección medioambiental, considerando ambas actuaciones como instrumentos de prosperidad económica, lo cierto es que las metas y los plazos no son siempre coincidentes, lo que genera una cierta dispersión en las acciones desplegadas y una falta de sinergia entre las diferentes estrategias. Así, la Estrategia 2020, el 7o Programa de Acción Medioambiental y la iniciativa emblemática "Una Europa que utilice eficazmente los recursos» tienen como horizonte temporal el año 2020. Por su parte, las hojas de ruta Hacia una economia hipocarbónica y Hacia una Europa eficiente en el uso de los recursos incluyen objetivos y actuaciones hasta 2050, mientras que el nuevo paquete sobre clima y energía considera el período 2021-2030 y el nuevo paquete y plan de acción para la economía circular contempla actuaciones desde 2016 a 2030. Consecuentemente, en aras a una mayor clarificación y efectiva implementación, sería deseable una simplificación de los múltiples marcos estratégicos y normativos, estableciendo sinergias que eviten solapamientos y confusión en las actuaciones a emprender por los diferentes agentes y ciudadanos implicados.

Asimismo, en el estudio de las medidas adoptadas por la UE para promover una economía eficiente en el uso de los recursos, se ha echado en falta la fijación de un objetivo concreto de reducción de materiales y recursos, a 
modo y semejanza de los establecidos para las emisiones de GEI, o el incremento de energías renovables y eficiencia energética. Ese objetivo concreto de reducción, acompañado de mecanismos adecuados de control y evaluación, permitiría tal vez encauzar de forma más precisa la implementación de las distintas iniciativas por parte de las autoridades competentes, los agentes económicos y la ciudadanía en general, así como medir exactamente los resultados conseguidos.

Aparte de sus actuaciones a nivel interno, la UE intenta promover el uso eficiente de los recursos a nivel global, especialmente en países pobres y en vías de desarrollo, como un aspecto fundamental de su política de cooperación al desarrollo sostenible. No obstante, el estudio ha destacado incoherencias relevantes entre el objetivo de la UE de promover el desarrollo sostenible y sus actuaciones de lucha contra el cambio climático, el uso eficiente de recursos y la seguridad alimentaria en los países pobres. Los mecanismos institucionales y los instrumentos para cumplir con la coherencia de políticas para el desarrollo, según se establece como obligación jurídica en el art. 208 TFUE, no han resultado efectivos por el momento, a la espera de la plena implementación del nuevo programa «Legislar mejor». Por tanto, cabe constatar que, en lo que se refiere a la dimensión exterior del uso eficiente de recursos, la UE no ha formulado una estrategia propia, específica y coherente en pro del desarrollo sostenible, en contraste a los múltiples marcos estratégicos adoptados en su ámbito interno. En cualquier caso, mientras los propios Estados miembros no cooperen en conseguir el objetivo de una gestión eficiente de recursos a nivel interno, la UE difícilmente podrá demostrar al mundo los beneficios de un modelo de economía circular y sostenible, perdiendo así credibilidad como actor mundial e incumpliendo, además, sus obligaciones de contribuir equitativamente a las cargas medioambientales.

La participación en una mejor gobernanza global para el consumo eficiente de recursos, asegurando al mismo tiempo que los países más vulnerables no queden relegados de este proceso, requerirá de una política exterior más activa y coherente. La Comisión Europea, en nombre de la UE, el Servicio Europeo de Acción Exterior, coordinando las diplomacias nacionales y el Parlamento Europeo, representando a los ciudadanos, deberían liderar y desempeñar juntos un papel activo en la coordinación de la acción exterior europea. A tal fin, podría pensarse en una estructura o grupo de trabajo conjunto, que formulara una única estrategia más holística para abordar el reto de la gestión eficiente de recursos, a nivel europeo y a escala global, definiendo a continuación los instrumentos y recursos financieros necesarios. Una estrategia integrada, en sus dimensiones interna y externa, aportaría más visibilidad, coherencia y consistencia a la acción global de la UE, contribuyendo así a mejorar la sostenibilidad a largo plazo de la economía europea y mundial. 
